\title{
Angeología adánica: los ángeles en la poesía de Martín Adán
}

\section{ADÁNICA ANGEOLOGY: ANGELS IN THE POETRY OF MARTÍN ADÁN}

A Gladys, mi ángel.

Andrés Piñeiro Mayorga

Universidad de Lima

\section{RESUMEN}

Martín Adán es, al lado de César Vallejo, uno de nuestros poetas fundamentales. Su obra, a pesar de la importancia que posee, no ha sido suficientemente estudiada. Por ejemplo, con respecto a los símbolos que alberga su poética, solo han sido elucidados los de la rosa y la piedra; pero no la única figura que ha permanecido en toda su producción: el ángel. Esta, si bien es cierto que no se ha desplegado como central en alguno de sus poemarios, como la rosa en Sonetos a la rosa 0 en Travesía de extramares (Sonetos a Chopin); y la piedra en La mano desasida. Canto a Machu Picchu o La piedra absoluta, no ha dejado de estar presente en ningún momento de su poesía, como sí lo han hecho los símbolos mencionados: cuando aparece la rosa, no asoma la piedra; cuando asoma la piedra, no aparece la rosa.

PALABRAS CLAVE: Martín Adán, cristianismo, herética, angeología, ángel

\section{ABSTRACT}

Martín Adán is, next to César Vallejo, one of our fundamental poets. His work, despite its importance, has not been sufficiently studied. For example, with regard to the symbols contained in his poetics, only those of the "rose" and the "stone" have been elucidated; but not the only figure that has remained throughout his production: the "angel". This, although it is true, has not been displayed as central in any of his poetry books, such as the "rose" in Sonetos a la rosa or Travesía de extramares. Sonetos a Chopin; and the "stone" in La mano desasida. Canto a Machu Picchu or La piedra absoluta, has not ceased to be present at any time in his poetry, as the aforementioned symbols have: when the "rose" appears, the "stone" does not appear; when the "stone" appears, the "rose" does not appear.

KEYWORDS: Martín Adán, Christianity, heretical, angeology, angel 
Todos hemos visto o creído ver; hemos escuchado o creído escuchar; hemos hablado o creído hablar; hemos tocado o creído tocar a un ángel. William Blake, Emanuel Swedenborg, Paul Klee, Wim Wenders, Rainer Maria Rilke, John Milton, Rafael Alberti, entre muchos otros, nos demostraron que la conocida sentencia nietzscheana sobre la divinidad, por algún motivo que no buscamos entender, dejó incólumes a los ángeles.

La obra poética de Martín Adán, si nos atenemos a los estudios literarios, discurre por cuatro etapas claramente definidas. En la primera, los poemas reunidos bajo el título de Itinerario de primavera y La rosa de la espinela llevan la marca inequívoca del vanguardismo. En la segunda, donde predominan los arcaísmos y las palabras con gran riqueza etimológica, el rigor formal del verso, expresado magníficamente en sonetos, y el hermetismo que, por momentos, hace inaccesible la comprensión de sus versos, tiene en Travesía de extramares (Sonetos a Chopin) su ejemplo más célebre. En la tercera, los versos adquieren un estilo que oscila entre lo coloquial y lo oracular, y muestran su esplendor en el Escrito a ciegas (carta a Celia Paschero) y La mano desasida. Canto a Machu Picchu. En la cuarta etapa, con Mi Darío y Diario de poeta, los sonetos se alejan del hermetismo del segundo momento para acercarse a un sutil tono conversacional.

No obstante, más allá de los cambios de tono, estilo, formas estróficas, etcétera, tenemos una visión cristiana del mundo que sustenta su labor poética. En nuestro ensayo La herética de Martín Adán. Cuestionamiento, alejamiento y confrontación con la tradición cristiana (Piñeiro, 2017), sostuvimos que dicha visión de Adán presenta dos momentos claramente definidos. El primero, en conformidad con los dogmas cristianos, puede apreciarse desde sus textos aparecidos bajo el título de Itinerario de primavera hasta Travesía de extramares (Sonetos a Chopin). El segundo, en clara distancia con tales dogmas, puede reconocerse desde Escrito a ciegas (carta a Celia Paschero) hasta Diario de poeta, su último poemario.

En la primera etapa poética de Martín Adán, atendiendo a su visión cristiana del mundo, que coincide con los dos primeros momentos de su poética según los estudios literarios, hallamos una conformidad con los conceptos fundamentales del cristianismo. Dios, sacrificio, éxtasis visionario, el mundo visto como un valle de lágrimas, el reino escatológico, son nociones adoptadas dogmáticamente por el poeta y se expresan de manera cabal en Travesía de extramares. En cambio, en la segunda etapa, que coincide con los dos momentos finales de su poética, hay un distanciamiento de los dogmas de la fe cristiana. En Escrito a ciegas (carta a Celia Paschero), por ejemplo, la salvación puede ser transferida a otra persona y ser condenatoria en vida, y no, como enseña la tradición cristiana, una acción intransferible que exige un sincero arrepentimiento: "Yo no quiero ya ser yo / Sino otro que se salvara o que se salve". Asimismo, la muerte puede pasar a ser una prerrogativa del ser humano y no un designio divino: "Porque vivo porque me mato". El hombre no es dueño ni de uno de sus cabellos, reza el Evangelio. 
No es casual que en las dos primeras etapas de su poesía, de acuerdo con los estudios literarios, y la primera si consideramos su visión del mundo, el símbolo predominante sea el de la rosa, figura de constante presencia en la literatura occidental. En las denominadas ripresas de Travesía de extramares, por ejemplo, Martín Adán da cuenta del éxtasis poético que experimenta en sus versos, de la dicotomía entre el mundo esencial y el terrenal, y de la fragilidad de la naturaleza humana, percibida como la maestra en su camino a la divinidad, en la comprensión de la realidad, del amor y en el anhelo de lo inefable. Y el símbolo que marcará la segunda y la tercera etapa, la segunda en su visión del mundo, será el de la piedra. Su persistencia desgarradora en los más de ocho mil versos que recorren La mano desasida. Canto a Machu Picchu nos mostrará la fortaleza de la piedra ante los embates del tiempo y su fragilidad ante las huellas humanas, el ascenso del poeta a la ciudadela incaica y el descenso a los confines de la conciencia humana, el abandono de la Creación y la persistencia de la piedra, el odio y la confrontación con el prójimo.

Observemos que ninguno de los símbolos permanece en toda la obra poética de Martín Adán. La rosa solo va a expandir sus pétalos en La rosa de la espinela, Sonetos a la rosa o en Travesía de extramares; la piedra solo se va a erigir con todo su misterio y majestad en La mano desasida. Canto a Machu Picchu o en La piedra absoluta. Sin embargo, hay una figura constante en toda la obra poética de Adán, el ángel. Este guarda las mismas características señaladas en la obra poética de nuestro autor: conformidad con los dogmas cristianos en la primera etapa y de distancia de dichos dogmas en la segunda.

En la primera etapa, vemos al "ángel de la anunciación" acompañar y referir a María el nacimiento de Jesucristo en el poema "Navidad" de Itinerario de primavera; anuncia a María el misterio de la encarnación. Amanece en el remoto puerto de Thule en Groenlandia, cambia los aguijones por "aureola de iris" en la corona de la crucifixión en los textos de La campana Catalina; aparece encarnando los deseos de eternidad en el tercer soneto de los dedicados a Alberto Ureta, y como la "realidad" que guía al poeta en "Ma inmoderato" de Travesía de extramares.

En la segunda etapa, el ángel que acompaña al poeta no es el de la "Guarda", sino el del "Hartazgo y Retazo" en Escrito a ciegas. Es el "ángel del estorbo" en La mano desasida. Es el "Ángel de las Cosas", inconsciente, impiadoso, torpe, sucio en Diario de poeta. Por ello, nos atrevemos a decir que Martín Adán logra configurar una "angeología" en la medida en que alcanza a darles vida a unos "ángeles" que van más allá de la tradición cristiana o de cualquier otra tradición y que solo apreciamos en su poesía.

Este texto se divide en dos partes claramente diferenciadas. En la primera, "Angeología cristiana", daremos cuenta de los ángeles que pueblan el cielo cristiano y que aparecen en las dos primeras etapas de la poesía de Martín Adán, de acuerdo con los estudios literarios, y la primera etapa, si seguimos su visión dogmática de la tradición 
cristiana. En la segunda, "Angeología adánica", haremos lo propio con los ángeles creados por el poeta y que aparecen en las dos últimas etapas de su poesía, según los estudios literarios, y la segunda etapa, si nos atenemos a su visión "herética" del cristianismo. Para tal fin, nos apoyaremos, principalmente, en la Biblia, el Catecismo de la Iglesia católica y en algunos poetas como John Milton o Rainer Maria Rilke.

Contamos con escasos estudios dedicados a la obra de Martín Adán si tomamos en cuenta su importancia. Ciertamente nos encontramos en una etapa inicial de nuestro acercamiento a uno de nuestros poetas mayores. Por ello, se entiende que dichos estudios indaguen por un aspecto específico de la producción de Adán: los símbolos de la rosa o la piedra, la influencia del cristianismo, la naturaleza de su poética, los fragmentos del "Aloysius Acker", una biografía, etcétera. Hasta ahora no se ha realizado un estudio que indague por la figura más persistente en la poesía de Martín Adán, el ángel. El presente artículo pretende iniciar este camino.

\section{ANGEOLOGÍA CRISTIANA}

Con los poemas reunidos bajo el título de Itinerario de primavera se inicia la primera etapa de la obra poética de Martín Adán atendiendo a su estilo y también la primera si seguimos a su visión del mundo en conformidad con los dogmas cristianos. Como ha señalado Mirko Lauer (1983) acerca del "ambiente" que rodea los poemas de Martín Adán que van desde "Navidad", perteneciente a Itinerario de primavera, hasta La rosa de la espinela, todos llevan la impronta del "vanguardismo español y leal a ciertos epígonos de la generación del 98 . Hay en ellos un leve, pero determinante predominio de la imagen sobre lo conceptual" (p. 14). En efecto, en "Navidad" prevalece claramente la imagen sobre el concepto, una presencia de los cuadros y colores de Leonardo da Vinci que invita a su contemplación. Es el primer texto de Adán donde aparece la figura del ángel.

En el Evangelio de Mateo, un ángel se aparece en los sueños de José y le anuncia la buena nueva: "Así lo tenía planeado, cuando el Ángel del Señor se le apareció en sueños y le dijo: 'José, hijo de David, no temas tomar contigo a María, tu mujer, porque lo engendrado en ella es del Espíritu Santo'" (Mt 1, 20-21). En el Evangelio de Lucas, un ángel anuncia el nacimiento de Jesús a los pastores:

Había en la misma comarca unos pastores, que dormían al raso y vigilaban por turno durante la noche su rebaño. Se les presentó el Ángel del Señor, y la gloria del Señor los envolvió en su luz; y se llenaron de temor. El ángel les dijo: "No temáis, pues os anuncio una gran alegría, que lo será para todo el pueblo: os ha nacido hoy, en la ciudad de David, un salvador, que es el Cristo Señor; y esto os servirá de señal: encontraréis un niño envuelto en pañales y acostado en un pesebre". Y una multitud de ángeles se unieron al Ángel del Señor y alabaron a Dios, diciendo: "Gloria a Dios en las alturas y en la tierra paz a los hombres en quienes él se complace". (Lc 2, 8-14) 
El anuncio de la llegada de Jesús es dado por un ángel a José y a los pastores; otros ángeles se reúnen con Él o elevan cánticos por su nacimiento. Martín Adán une estos dos momentos bíblicos diferenciados, la anunciación y el nacimiento de Jesús, en un solo texto. En la tradición cristiana, la Navidad comprende el período que va desde la Nochebuena hasta la festividad de los Reyes Magos.

El poema se inicia con una evocación a las "madonnas", a las "vírgenes", de Leonardo da Vinci, primeras obras pictóricas del artista florentino. Podría tratarse de la Virgen con el Niño y flores, más conocida como la Madonna Benois, donde las miradas de María y su Hijo se detienen en la complicidad de sus manos. 0 a La Virgen de las rocas, por su evocación a la "gruta del cielo" y "el rebaño del mar". También podría estar tomando como referencia a La Virgen del huso. No descartaríamos la posibilidad de la presencia de estas tres obras en el poema que analizamos, las cuales le otorgan su peculiaridad a cada fragmento del texto. Según el poeta, se trata de una obra del Renacimiento "sombrío", apreciado como un movimiento de transición entre el Medioevo y la modernidad, y no en el resplandor que evoca su nombre.

El "rebaño del mar" nos remite a las tareas de pastoreo del pueblo hebreo, pero este no viene del valle, sino del mar, y "bala" a la "gruta del cielo". Esta nos hace pensar en el cielo como "una inmensa bóveda de cristal tachonada de estrellas fijas", descrita por Aristóteles, un lugar sólido, límite del mundo, y no como un espacio abierto al infinito. Como señalamos líneas arriba, "el rebaño del mar" y "la gruta del cielo" podrían guardar relación con La Virgen de las rocas, donde apreciamos estas características. Leamos estos versos de "Navidad": "El rebaño del mar / bala a la gruta / del cielo, llena de ángeles". (Martín Adán, 1980, p. 3). El poema termina aludiendo a los juegos del Niño, al amor de la madre y al lecho del Niño. En La Virgen del huso, el Niño juega con este instrumento, que podría evocar la inocencia de Jesús ante la crucifixión futura, ya que el huso tiene forma de cruz. Los "labios" de María dan el "calor" que "niegan la vaca y el asno", con lo que se enfatiza las tareas de pastoreo, pero que marcan una distancia abismal con el amor maternal. El lecho del Niño está formado por los cabellos de María.

Es interesante comprobar la afinidad que guarda "Navidad" de Martín Adán con Himno a la natividad de John Milton. En este poemario también se refiere el nacimiento del Hijo de Dios y se insiste en el nuevo orden cósmico que instaura: declinan otras creencias, los astros se detienen, Satán recibe un nuevo castigo. Aquí los ángeles emiten una intensa melodía con sus alas para adorar al Hijo enviado:

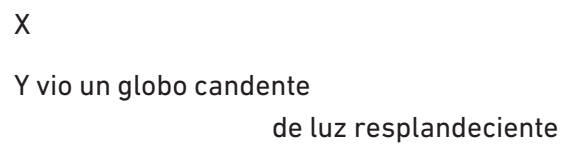


y armados serafines

volando en fila con radiantes alas,

y como de arpas escuchó el tañido

por el Hijo de Dios recién nacido. (Milton, 2009, p. 29)

También aparecen los ángeles cantando “¡Hosanna!”-del arameo y sus derivaciones hebrea, griega y latina, "salva", "rescate”, "salvador"- al Hijo de Dios en el pesebre. María ya no canta y la "estrella postrera" se ha detenido y encendido su lámpara. Llama la atención que Milton emplee este cántico en el nacimiento de Jesús, ya que se le suele utilizar en el cristianismo en el Domingo de Ramos y en la eucaristía:

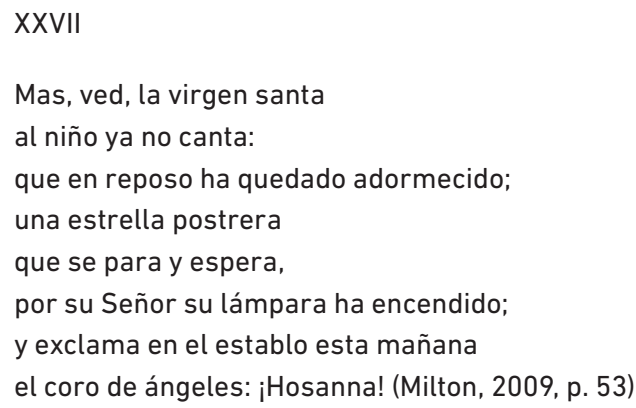

En "Navidad" de Martín Adán, aparecen los "ángeles" para anunciar y acompañar el nacimiento de Jesús. En "Natividad" de John Milton, aparecen para adorar el nacimiento del Hijo del Hombre con sus cánticos. Asimismo, en ambos casos, se apela a la pintura o iconografía cristiana. Martín Adán, como se anuncia en el poema, se remite a las "madonnas" de Leonardo. El texto de John Milton, según George Sampson, guarda afinidad con "un cuadro italiano de los primitivos que representa la natividad". En su Historia de la literatura inglesa, leemos:

Contemporánea de la sexta elegía latina es la oda On the Morning of Christ's Nativity, tan llena de vigorosa fantasía y originales bellezas; como un cuadro italiano de los primitivos que representara la natividad, se halla llena de apacibles, atrayentes detalles, y también de los mismos patéticos recursos. Es única en la poesía inglesa, y única en Milton mismo, pues cuando intentó la realización de otro poema del mismo género, The Passion, no lo logró, y siendo él el poeta de más sentido autocrítico comprendió su fracaso y así lo dijo. (Como se citó en De Vedia y Mitre, 2009, p. 11)

Por la mente de Martín Adán transitan las imágenes de las "madonnas" de Leonardo y él va cogiendo algunas características que conformarán cada fragmento de su poema. Milton hace lo propio con los cuadros de los "primitivos" sobre la natividad. Nos apena que esta evocación de las "madonnas" - o de otros temas pictóricos- no haya permanecido en la obra poética de Martín Adán. Sin duda, habríamos tenido otros poemas o poemarios tan notables como el que acabamos de analizar. Leonardo da Vinci con La Virgen 
del clavel, John Milton con Himno a la natividad y Martín Adán con "Navidad" iniciaron sus obras bajo el esplendor de la misma estrella.

La campana Catalina de Martín Adán, como señala John Kinsella (1989), se caracteriza, si nos atenemos a su estilo, como toda la segunda etapa del poeta donde también encontramos La rosa de la espinela y Travesía de extramares (Sonetos a Chopin), "por su preferencia por una poesía más ordenada y disciplinada" (p. 190). Y si consideramos su visión cristiana del mundo, continúa en La campana Catalina la primera etapa de su poética. Ciertamente, se trata de su etapa barroca, hermética, donde proliferan los arcaísmos y se erige a la rosa como su símbolo más importante.

En La campana Catalina se da cuenta del ángelus. Esta es una oración que nos recuerda el anuncio del ángel a María sobre su divina maternidad, es decir, el misterio de la encarnación. En honor a este misterio, el papa Juan XXII (1244-1334), a quien se le atribuye la autoría del rezo, ordenó a sus fieles que al tañer de las campanas de los templos se iniciara dicha oración. En el mencionado poemario de Adán, las "campanas" recuerdan al "ángel de la anunciación" su cometido, como si cada vez que tañen las campanas se reiniciara el misterio: “¡Callándote, que no te oye!... / ¡Das el ángelus al ángel! / ¡Que la Catalina habla / como si le faltara el aire!" (Martín Adán, 1980, p. 39). En los siguientes versos, el poeta nos sitúa nuevamente en el escenario descrito en el poema "Navidad" de Itinerario de primavera. La sorpresa ante el anuncio del "ángel" y las manos y las miradas que intercambian madre e Hijo: "Cuando en casa sin aliento, / presente aún el ángel, / desnudan un lecho manos / mudas, ciegas, de una madre" (Martín Adán, 1980, p. 49).

La corona de espinas colocada cruelmente a Jesucristo como escarnio por su pretendida divinidad antes de su camino a la crucifixión se desvanece en una "aureola de iris". El término élitros afianza la idea de transformación de los "aguijones" en "aureola". En la definición que da la Real Academia Española (s. f.) de élitros, leemos:

Cada una de las dos alas anteriores de los ortópteros y coleópteros, las cuales se han endurecido y en muchos casos han quedado convertidas en gruesas láminas córneas, que se yuxtaponen por su borde interno y protegen el par de alas posteriores, las únicas aptas para el vuelo. (Definición 1)

Esta situación puede ser entendida como el tránsito de la ofensa humana a la piedad divina, de la figura desgarradora de la "corona de aguijones" a la figura salvadora de una "aureola de iris de élitros la truecan ángeles". Nos dice el poeta: "La corona de aguijones / de las sienes se te cae, / y en aureola de iris / de élitros la truecan ángeles" (Martín Adán, 1980, p. 55). Los ángeles, según la tradición cristiana, no están presentes en la crucifixión de Jesucristo. Sin embargo, el poeta alivia el destino cruento que le espera al Niño que acaba de nacer con unos "ángeles" que transforman la "corona de aguijones" en una "aureola de iris". 
Con Travesía de extramares (Sonetos a Chopin), asistimos al poemario mejor estructurado de Martín Adán. Los poemas se van sucediendo como momentos musicales en torno al poeta peruano Alberto Ureta, maestro de Adán en el Colegio Alemán; a la búsqueda de lo inefable; a Chopin, como reza el "subtítulo" del poemario; y a la rosa, el símbolo principal de esta época. Seguimos con la segunda época de su poesía según su estilo, donde predomina su barroquismo y hermetismo; y llegamos al fin de la primera, tomando en cuenta su visión cristiana del mundo.

Los poemas a Ureta aparecieron con anterioridad en Itinerario de primavera y las ripresas, los ocho sonetos dedicados a la rosa, fueron elegidos entre los nueve que conformaron Sonetos a la rosa. En el tercer soneto dedicado a Alberto Ureta en Travesía de extramares, la figura del ángel aparece adjetivada en "angélico afán". Se enfatiza así esa actitud cristiana en Martín Adán que consiste en separar el mundo celestial, en el que habitan los ángeles y al que aspira el alma humana, del mundo terrenal, del "valle de lágrimas" en el que mora nuestro cuerpo. Ese "alivio", que consiste en experimentar el éxtasis poético que ha logrado el maestro Ureta, quiere tenerlo el discípulo Adán, pero no logra conseguirlo del todo: “ ¡Quiero aliviarme, no en seguro ajeno, / Sino en el propio mío, en la mi nada, / Del angélico afán y cuerpo humano!" (Martín Adán, 1980, p. 89).

Como sabemos, ripresa es un término musical que designa ocho movimientos en una composición. En Travesía de extramares, tenemos ocho ripresas que conforman el núcleo del poemario. En "Sesta ripresa", encontramos la evocación del poeta de una identidad efímera que se alcanza mediante el éxtasis visionario con la rosa. El poeta se reconoce como distinto y distante la naturaleza de la rosa; esta se ve como un ser externo que acude al poeta en el instante de la creación, que no es, por cierto, un momento enteramente grato, en la medida en que no es su condición natural. Leamos la "Sesta ripresa":

La rosa que amo es la del esciente,

La de sí misma, al aire de este mundo;

Que lo que es, en ella lo confundo

Con lo que fui de rosa, y no de mente.

Si en la de alma espanta el vehemente

Designio, sin deseo y sin segundo,

En otra vence el incitar facundo

De un ser cabal, deseable, viviente...

Así el engaño y el pavor temidos,

Cuando la rosa que movió la mano

Golpea adentro, al interior humano...

Que obra alguno, divino por pequeño,

Que no soy, y que sabe, por los sidos

Dioses que fui ordenarme asá ensueño. (Martín Adán, 1980, p. 106) 
En este soneto apreciamos la separación de cuerpo y mente. El poeta ama a la rosa etérea poseedora del saber y que no ha podido ser alcanzada a cabalidad, debido a que la naturaleza del poeta está constituida no solo de alma, sino también de cuerpo. Las cualidades inmateriales, al no poseer atributos tangibles, pueden resultar frustrantes en oposición a los "vivientes". No obstante, las cualidades inmateriales se tornan presentes en el cuerpo, "movió la mano", y en el alma del poeta, "el interior humano", procurándole una experiencia dolorosa. No en vano G. W. F. Hegel llama angustia al sentimiento de pérdida total del ser ante la muerte. La creación es un atributo que puede compartir con la divinidad, a pesar de sus limitaciones humanas.

\section{ANGEOLOGÍA ADÁNICA}

Un tono conversacional marca la tercera etapa de la poética de Martín Adán, de acuerdo con los estudios literarios, y una herética si nos atenemos a su visión cristiana del mundo donde predomina su "herética". En el Escrito a ciegas, vemos que el poeta no se identifica con el Ángel de la Guarda, presente en las oraciones de la más tierna infancia, sino con el del Hartazgo y Retazo. Un ángel con dos rostros. El "Ángel del Hartazgo" ha logrado colmar sus deseos, incluso en exceso. El "Ángel del Retazo" evoca su propia escritura, hecha de fragmentos. Por un lado, la propia revelación de la vida misma se nos muestra en sus experiencias aisladas e intensas, la "duración" de la que nos hablaba Henri Bergson, que el poeta recrea en el poemario, y no en su continuidad anodina. Por otro lado, podemos ver en esta identificación con el "Ángel del Retazo" una clave para leer su propia obra poética, sobre todo en Escrito a ciegas y en La mano desasida. Al final de la lectura de estos poemarios nos queda la sensación de que, si cambiáramos el orden de los fragmentos, esto no alteraría en lo más mínimo su consecución final.

Mi Ángel no el de la Guarda.

Mi Ángel es del Hartazgo y Retazo,

Que me lleva sin término,

Tropezando, siempre tropezando,

En esta sombra deslumbrante

Que es la vida, y su engaño y su encanto. (Martín Adán, 1980, p. 145)

Sería interesante relacionar el tránsito de la conformidad con el dogma cristiano hacia la herejía poética en la obra de Martín Adán con el tránsito de la poesía de Rilke de la presencia de Dios en El libro de las horas a su casi ausencia en Las elegías de Duino, donde la figura del ángel se erige como el nuevo destino de sus versos. Incluso, en la aparición de la figura rilkeana del ángel terrible, podemos escuchar ecos lejanos del "Ángel del Hartazgo y Retazo" martinadánico. En ambos casos, no apreciamos el rostro bello y amable del ángel, sino su rostro cruel, altivo y distante. El propio Rilke le escribe en una carta a su amigo W. von Hulewicz: "El 'Ángel' de las Elegías no tiene nada que ver 
con el ángel del cielo cristiano (sino más bien con las figuras de ángeles del islam)" (carta a W. von Hulewicz, XIII, 334-337, como se citó en Angelloz, 2016, p. 29). Los ángeles del islam son seres de luz que siguen las órdenes de Dios y, por lo tanto, no pueden revelarse contra Él. No encontramos la figura del ángel caído, ni la conversión de ángeles en hombres, ni de hombres en ángeles. Rilke en los ángeles del islam y Martín Adán en los creados por él expresaron la tragedia de una separación originaria entre seres celestiales y terrenales.

La mano desasida. Canto a Machu Picchu es el poemario más extenso de Martín Adán, más de ocho mil versos, y, para algunos estudiosos como Mirko Lauer, el más trascendente. Ciertamente, estamos frente a un poemario tan colosal como la ciudadela inca que le da su nombre. Continuamos en la tercera etapa de su poesía, según su estilo, y la segunda atendiendo a su visión "herética" del mundo, cada vez más radical.

En los siguientes versos de "Escrito para una amiga" de La mano desasida, la figura del ángel adquiere un nuevo rostro, el del "estorbo"; pero, a pesar de ser un obstáculo para el poeta, este lo asume como propio y también como la fuerza que lo empuja a escribir sobre su travesía por la ciudadela inca con las dificultades físicas y mentales que conlleva tal experiencia. La confrontación con el "ángel del estorbo" le revela al poeta su tránsito por la vida, lo efímero de su existencia, su fatiga, en una palabra, su humanidad:

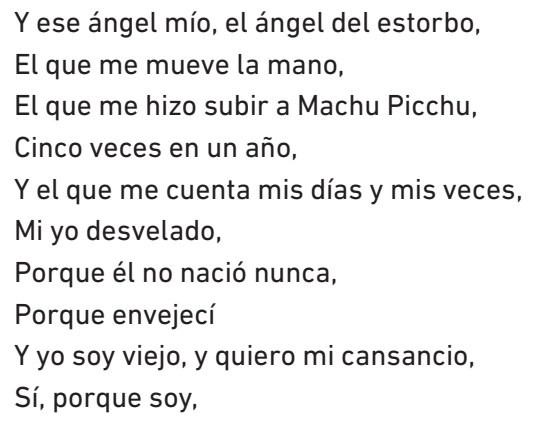

El "ángel del estorbo" es el que lo ayuda a realizar su escritura, que es asumida por Martín Adán como una desnaturalización de lo que ha podido "oír de las sumas voces" cuando evocaba la figura del poeta Alberto Ureta en Travesía de extramares y que ahora se asume como lo "intraducible". Dicho ángel hace patente las dificultades físicas y mentales a la hora de realizar una tarea de la envergadura de la poesía o del ascenso a Machu Picchu. Asimismo, con el "ángel del estorbo" se acrecienta su actitud herética al presentarlo como una realidad que le muestra las limitaciones de su naturaleza terrenal.

Machu Picchu también es visto como una "Estatua de Luzbel", el ángel más bello y arrogante que abandona su hábitat celestial para crear su propio reino infernal. Una caída que se precipita a la tierra o dentro de ella. Es interesante que el poeta tome uno 
de los dos rasgos más notorios de Luzbel que, como ha señalado santo Tomás de Aquino en su "Tratado de los ángeles" de la Suma teológica (1 q.63 a.3), es la soberbia. El otro, la envidia. Leemos en La mano desasida:

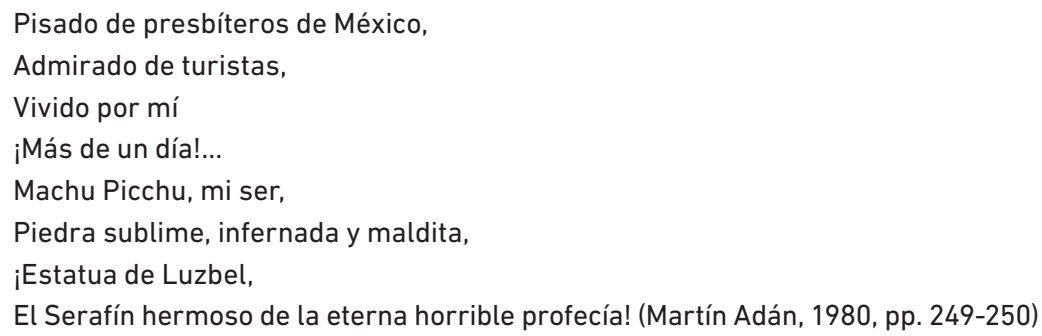

Diario de poeta (1973), último poemario publicado por Martín Adán, marca el final de ambas clasificaciones de su poética: la segunda etapa de su poesía, si nos atenemos su visión "herética" de la tradición cristiana, y la cuarta si seguimos a los estudios literarios. Apreciamos que dicha visión ha llegado a su punto más álgido con respecto a la tradición cristiana. En poemarios anteriores, hemos apreciado "alejamiento y cuestionamiento"; ahora veremos una clara "confrontación". En cuanto a su estilo, se observa una vuelta al soneto, pero sin los rigores conceptuales observados en Travesía de extramares. Su hermetismo y barroquismo han cedido al tono coloquial propio de los diarios.

En el siguiente terceto, también se pueden apreciar las propiedades humanas del poeta transferidas al "Ángel de las Cosas": "Necio y barbudo loador de rosas / Y bebedor de vino el como humano". También Martín Adán se refiere a su propia labor poética del primer momento como "loador de rosas", tal como escribe en La rosa de la espinela, Sonetos a la rosa o en las ripresas de Travesía de extramares. En Diario de poeta, leemos: "¡Y así abrumado el Ángel de las Cosas, / Necio y barbudo loador de rosas / Y bebedor de vino el como humano!" (Martín Adán, 1980, p. 447).

En los versos que siguen, el ángel es visto como una figura que lo agobia, "Pegadizo Ángel", que torna innecesaria su presencia, ya que el poeta puede unirse a Dios cuando lo alcance la muerte o cuando esta se prefigure en el éxtasis poético: “¡Vete, pues, Pegadizo Ángel, adelante... / Que Dios me está esperando en cada instante!... / ¡Al ente divinal, por Su demora!..." (Martín Adán, 1980, p. 448).

Hemos podido apreciar en el presente artículo que la figura del ángel abarca toda la obra poética de Martín Adán. No hay otra figura o símbolo, como el de la rosa o el de la piedra, que tenga esa presencia. La rosa expande sus pétalos en las dos primeras etapas de su poética, si seguimos a los estudios literarios, y en la primera si nos atenemos a su visión cristiana del mundo, que va desde sus primeros poemas hasta Travesía de extramares; pero no está presente en la tercera y cuarta etapa de su poética mencionadas por los estudios literarios y la segunda de acuerdo con su visión del mundo, que va desde 
Escrito a ciegas hasta Diario de poeta, donde predomina su distanciamiento de la tradición cristiana y se erige la piedra como el símbolo más importante. Este ciertamente no aparece en los primeros poemarios. Es interesante notar que el cambio de perspectiva de dicha tradición, "dogmática" en el primer momento y "herética" en el segundo, también se vea reflejada en los "ángeles". Estos guardan conformidad con el universo cristiano en el primer momento y se tornan heréticos en el segundo, al punto de referirnos a ellos como creaturas adánicas.

\section{REFERENCIAS}

Angelloz, J. F. (2016). Las Elegías de Duino y los Sonetos a Orfeo. Prólogo. En R. M. Rilke, Elegías de Duino. Sonetos a Orfeo. Lima: Academia Peruana de la Lengua.

Aquino, T. de (2014). Suma teológica. Madrid: Biblioteca de Autores Cristianos.

Catecismo de la Iglesia católica. (1993). Lima: Misión Jubilar Lima, Perú.

Kinsella, J. (1989). Lo trágico y su consuelo. Estudio de la obra de Martín Adán. Lima: Mosca Azul Editores.

Lauer, M. (1983). Los exilios interiores. Lima: Mosca Azul Editores.

Martín Adán (seud. de Rafael de la Fuente). (1980). Obra poética (edición, prólogo y notas de R. Silva-Santisteban). Lima: Edubanco.

Milton, J. (2009). Himno a la natividad. Lima: Rectorado de la Pontificia Universidad Católica del Perú, colección Manantial Oculto.

Piñeiro, A. (2017). La herética de Martín Adán. Alejamiento, cuestionamiento y confrontación con la tradición cristiana. Lima: Academia Peruana de la Lengua.

Real Academia Española. (s. f.). Diccionario de la lengua española. Recuperado de https:// dle.rae.es

Rilke, R. M. (2016). Elegía de Duino. Sonetos a Orfeo. Lima: Academia Peruana de la Lengua. Vedia y Mitre, M. de. (2009). Presentación. En J. Milton, Himno a la Natividad. Colección El Manantial Oculto, dirigida por Ricardo Silva-Santisteban. Lima: Pontificia Universidad Católica del Perú, Rectorado. 